\title{
Targeted Intraoperative Radiotherapy During Breast-conserving Surgery for Breast Cancer in Patients After Implant Augmentation
}

\author{
HANS-CHRISTIAN KOLBERG ${ }^{1}$, VALERY UHL ${ }^{2}$, SAMUELE MASSARUT ${ }^{3}$, \\ DENNIS HOLMES ${ }^{4}$, CORNELIA KOLBERG-LIEDTKE ${ }^{5}$, \\ ERICA WHINERAY KELLY ${ }^{6}$, GYÖRGY LÖVEY ${ }^{7}$ and JAYANT S. VAIDYA ${ }^{8}$ \\ ${ }^{1}$ Marienhospital Bottrop, Bottrop, Germany; \\ ${ }^{2}$ Epic Care, Emeryville, CA, U.S.A.; \\ ${ }^{3}$ Centro di Riferimento Oncologico di Aviano, Aviano, Italy; \\ ${ }^{4}$ John Wayne Cancer Institute, Santa Monica, CA, U.S.A.; \\ ${ }^{5}$ Charité -Universitätsmedizin Berlin, Campus Charité Mitte (CCM), Berlin, Germany; \\ ${ }^{6}$ Auckland Breast Centre, Auckland, New Zealand; \\ ${ }^{7}$ BORAD, Bottrop, Germany; \\ ${ }^{8}$ University College London, London, U.K.
}

\begin{abstract}
Background/Aim: Targeted intraoperative radiotherapy (TARGIT IORT) is an option during breastconserving surgery (BCS). No data have yet been published regarding the safety of TARGIT IORT with implants in situ. TARGIT IORT is an attractive option in this context because of the risk of capsular fibrosis following external beam radiotherapy $(E B R T)$ in such patients. Patients and Methods: We are reporting a retrospective analysis of 16 patients who received TARGIT IORT during BCS for early breast cancer after previous implant-based breast augmentation. TARGIT IORT was performed using the Intrabeam ${ }^{T M}$ method. Results: Follow-up varied from 98 to 5 months. There were no procedure-related complications. One patient developed local recurrence after 36 months of follow-up. Among the remaining patients (15/16), no breast-cancer-related events occurred. Conclusion: This series of patients with TARGIT IORT during BCS after implant-based breast augmentation revealed no safety concerns and gives some confidence in discussing this option with selected patients.
\end{abstract}

Since the results of the TARGIT A trial demonstrating noninferiority of targeted intraoperative radiotherapy (TARGIT

This article is freely accessible online.

Correspondence to: Priv.-Doz. Dr. med. Hans-Christian Kolberg, Klinik für Gynäkologie und Geburtshilfe, Marienhospital Bottrop gGmbH, Josef-Albers-Str. 70, 46236 Bottrop, Germany. Tel: +4920411061601, e-mail: hans-christian.kolberg@mhb-bottrop.de

Key Words: Breast-conserving surgery, breast cancer, TARGIT IORT.
IORT) compared to external beam radiotherapy (EBRT) in selected patients with early breast cancer have been presented (1), TARGIT IORT has become an option during breast conserving surgery in over 350 centers in 35 countries and over 20,000 patients have been treated. In cases where TARGIT IORT seems not appropriate due to an increased risk of recurrence, the technique is often used as an anticipated boost. The oncological safety of this concept has also been demonstrated $(2,3)$. In addition to non-inferiority regarding local control, a positive impact of intraoperative radiotherapy on overall survival has been proposed. In the TARGIT A trial, the effect of TARGIT IORT on overall survival had an enhancing trend and in a retrospective analysis of patients after neoadjuvant chemotherapy who received TARGIT IORT as an anticipated boost, this effect was statistically significant (2). A recent meta-analysis confirmed the survival benefit of targeted radiotherapy (3).

A growing number of women are undergoing breast augmentation with implants. In the United States in 2016, over 310,000 breast augmentations were performed, representing an increase of over $200 \%$ compared to 1996 (4). The growing demand for breast augmentation will increase the number of patients with breast cancer and implants in situ. In cases with implant breast augmentation, breast conserving surgery and whole breast irradiation have been associated with capsular contracture rates as high as $65 \%$ (5). We were aware of the fact that in TARGIT centers TARGIT IORT was offered in selected cases of patients with breast cancer and implants in situ in order to avoid this complication. Here, we are presenting a series of 16 cases and discuss the feasibility and safety of TARGIT IORT in patients with implants. 
Table I. Patient characteristics.

\begin{tabular}{|c|c|c|c|c|c|c|c|c|c|c|c|}
\hline ID & $\begin{array}{c}\text { ER/PR/ } \\
\text { HER2 }\end{array}$ & Grade & $\begin{array}{c}\text { Sentinel } \\
\text { nodes }\end{array}$ & $\begin{array}{l}\text { Tumor } \\
\text { size } \\
(\mathrm{mm})\end{array}$ & $\begin{array}{l}\text { Distance } \\
\text { implant to } \\
\text { tumor }(\mathrm{mm})\end{array}$ & $\begin{array}{c}\text { EBRT } \\
\text { after } \\
\text { IORT }\end{array}$ & $\begin{array}{l}\text { Age at time } \\
\text { of surgery to } \\
\text { IORT (years) }\end{array}$ & $\begin{array}{c}\text { Time from } \\
\text { augmentation }\end{array}$ & $\begin{array}{l}\text { Implant } \\
\text { position } \\
\text { (months) }\end{array}$ & $\begin{array}{c}\text { Implant } \\
\text { type }\end{array}$ & $\begin{array}{l}\text { Follow-up } \\
\text { time }\end{array}$ \\
\hline 1 & Pos/pos/neg & 2 & pN1mi(sn) & 9 & 5 & No & 52 & 4 & Prepectoral & Silicone & 62 \\
\hline 2 & Pos/neg/neg & 2 & $\mathrm{pNO}(\mathrm{sn})$ & 19 & 12 & Yes & 56 & 13 & Prepectoral & Silicone & 54 \\
\hline 3 & Pos/pos/neg & 3 & $\mathrm{pNO}(\mathrm{sn})$ & $\begin{array}{l}0.8+ \\
\text { DCIS }\end{array}$ & 5 & Yes & 45 & 20 & Subpectoral & Not reported & 32 \\
\hline 4 & Pos/pos/neg & 2 & $\mathrm{pNO}(\mathrm{sn})$ & 6 & 11 & No & 49 & 4 & Prepectoral & Silicone & 15 \\
\hline 5 & Pos/pos/neg & 3 & $\mathrm{pNO}(\mathrm{sn})$ & 7 & 1 & Yes & 50 & 3 & Prepectoral & Silicone & 14 \\
\hline 6 & Pos/pos/neg & 1 & $\mathrm{pNO}(\mathrm{sn})$ & 5 & 15 & No & 49 & 16 & Subpectoral & Saline & 14 \\
\hline 7 & Pos/pos/neg & 2 & $\mathrm{pNO}(\mathrm{sn})$ & 7 & Not reported & No & 43 & Unknown & Subpectoral & Saline & 37 \\
\hline 8 & Pos/pos/na & $\begin{array}{c}1 \\
\text { (DCIS) }\end{array}$ & N/A & 15 & Not reported & No & 55 & Unknown & Subpectoral & Silicone & 98 \\
\hline 9 & Pos/pos/neg & 2 & $\mathrm{pNO}(\mathrm{sn})$ & 15 & Not reported & No & 75 & 2 & Subpectoral & Silicone & 25 \\
\hline 10 & Pos/neg/neg & 1 & $\mathrm{pNO}(\mathrm{sn})$ & 14 & 4 & No & 46 & 10 & Prepectoral & Silicone & 52 \\
\hline 11 & Pos/pos/neg & 2 & $\mathrm{pNO}(\mathrm{sn})$ & 9 & 1 & No & 63 & 20 & Prepectoral & Saline & 28 \\
\hline 12 & Pos/pos/neg & 2 & $\mathrm{pNO}(\mathrm{sn})$ & 7 & 5 & No & 49 & 25 & Prepectoral & Silicone & 18 \\
\hline 13 & Pos/pos/neg & 1 & $\mathrm{pNO}(\mathrm{sn})$ & 8 & Not reported & No & 57 & Unknown & Subpectoral & Saline & 5 \\
\hline 14 & Pos/pos/neg & 2 & pNO(sn) & 7 & Not reported & No & 60 & 10 & Subpectoral & Saline & 6 \\
\hline 15 & Pos/pos/neg & 2 & $\mathrm{pNO}(\mathrm{sn})$ & 17 & Not reported & No & 48 & Unknown & Subpectoral & Saline & 72 \\
\hline 16 & Pos/pos/na & $\begin{array}{c}2 \\
\text { (DCIS) }\end{array}$ & N/A & 2 & Not reported & No & 47 & 6 & Subpectoral & Silicone & 84 \\
\hline
\end{tabular}

\section{Patients and Methods}

This is a retrospective analysis of 16 patients from centers of the TARGIT group in Germany, Italy, New Zealand and the USA who had breast conserving surgery for early breast cancer, had undergone breast augmentation with implants before and wanted their implants to stay in situ. All patients were informed that no published data existed regarding TARGIT IORT over implants and gave their informed consent for this individual approach. The project of collecting data in this indication from centers of the TARGIT group worldwide was submitted to the local ethics committee in the corresponding author's institution on March 5, 2017, and approved by the committee. Patients have given their written informed consent.

All patients received TARGIT IORT using the Intrabeam ${ }^{\mathrm{TM}} 50 \mathrm{kV}$ $\mathrm{X}$-ray device delivering $20 \mathrm{~Gy}$ at the surface of the tumor bed. In 15 cases, TARGIT IORT was performed during the initial breast conserving surgery; one case was performed at a re-excision. After breast conserving surgery, all patients were presented to their local multidisciplinary tumor boards. Three patients received additional EBRT after TARGIT IORT because of the presence of extensive intraductal component or lymphovascular invasion. Patients were included if a basic dataset including immunohistochemistry, grade, nodal status and tumor size was available and at least one follow-up was documented.

\section{Results}

Patient characteristics are shown in Table I. Follow-up varied from 98 months to 5 months. Fourteen patients presented with invasive breast cancer. Two patients were diagnosed with ductal carcinoma in situ (DCIS). There were no procedure- related complications and none of the patients needed their implant to be removed. One patient (ID 7) was diagnosed with a local recurrence in a distant quadrant after 36 months of follow-up. In 15/16 patients no breast-cancer-related events occurred.

\section{Discussion}

Cases of patients with implants and breast-conserving therapy for breast cancer have initially been reported more than 30 years ago when the standard surgical therapy was still considered to be mastectomy (6). Since then, there have been individual approaches of de-escalation in cases of breast cancer after breast augmentation. Although the high incidence of capsular contracture after whole breast irradiation is a well-known risk in augmented patients, small case series with up to 20 patients showed that breast conserving surgery with consecutive radiotherapy is feasible $(7,8)$. However, smaller series describe an increased risk of cosmetic failure after EBRT with as many as 8 out of 11 patients in one series rating their cosmetic result as moderate or even worse (9). The risk of cosmetic failure was demonstrated to be even higher in patients receiving not only whole breast irradiation but also a boost to the tumor bed (10). The use of a brachytherapy boost instead of an external boost yielded favorable cosmetic outcomes even though patients received additional whole breast irradiation (11). A report on partial breast irradiation after implant-based breast augmentation comprised 16 patients treated with external 
beam accelerated breast irradiation (38.5 Gy in 10 fractions over 5 days) after breast conserving surgery (12). Follow-up varied from 1.2 to 58 months. Patients were satisfied with individual cosmetic results, reported no pain and remained disease-free during the follow-up period. Another retrospective analysis from a single center comprised 250 augmented patients who received interstitial brachytherapy. With follow-up of up to 20 years, fewer than $5 \%$ of patients experienced new-onset or worsening capsular contracture (13). However, tumor control, survival rates, cosmetic outcomes, and toxicities other than capsular contracture in this series have not been reported.

Our data represent the sole results of follow-up after partial breast irradiation using a $50 \mathrm{kV} \mathrm{X}$-ray-source to give targeted intraoperative radiotherapy in the context of breastconserving surgery for breast cancer after implant-based breast augmentation. There were no procedure-related complications and no cases that had loss of implant or needed exchange of the implant. We are aware of the limitations of our analysis, such as the inhomogeneous follow-up between 5 and 98 months, the small dataset due to the retrospective nature of our data from four different health systems and the small number of patients. However, the fact that there were no safety signals, neither complication-related nor breast cancer-related, facilitates discussing the option of TARGIT IORT with selected patients on an individual basis and warrants efforts for increasing the existing database including a prospective evaluation of cosmetic satisfaction and disease-free survival.

\section{Conclusion}

This series of patients with TARGIT IORT during breastconserving surgery for early breast cancer after breast augmentation with implants in situ revealed no safety concerns and gives some confidence in discussing this option among suitable patients. To expand this series, we are gathering details about other cases from the whole TARGIT group worldwide.

\section{Conflicts of Interest}

Dr. Kolberg reports personal fees from Carl Zeiss meditec, personal fees from Theraclion SE, personal fees from Genomic Health, personal fees from Novartis, personal fees from Pfizer, personal fees from Roche, non-financial support from LIV Pharma, personal fees from TEVA, personal fees from Riemser, personal fees from Janssen-Cilag, personal fees from Astra Zeneca, outside the submitted work. Dr. Uhl has nothing to disclose. Dr. Massarut reports other from Carl Zeiss meditec, outside the submitted work. Dr. Holmes has nothing to disclose. Dr. Kolberg-Liedtke has nothing to disclose. Dr. Whineray Kelly reports other from Focus Radiotherapy, outside the submitted work. Dr. Lövey has nothing to disclose. Dr. Vaidya reports personal fees and non-financial support from Carl Zeiss meditec, outside the submitted work.

\section{Authors' Contributions}

HCK, VU and JSV developed the idea of this analysis. HCK, VU, SM, DH, GL, EWK contributed in the data collection. HCK, VU, SM, DH, GL, EWK, CKL and JSV contributed in analyzing the data and writing the manuscript.

\section{References}

1 Vaidya JS, Wenz F, Bulsara M, Tobias JS, Joseph DJ, Keshtgar M, Flyger HL, Massarut S, Alvarado M, Saunders C, Eiermann W, Metaxas M, Sperk E, Sütterlin M, Brown D, Esserman L, Roncadin M, Thompson A, Dewar JA, Holtveg HM, Pigorsch S, Falzon M, Harris E, Matthews A, Brew-Graves C, Potyka I, Corica T, Williams NR and Baum M; TARGIT trialists' group: Risk-adapted targeted intraoperative radiotherapy versus wholebreast radiotherapy for breast cancer: 5-year results for local control and overall survival from the TARGIT-A randomised trial. Lancet 383(9917): 603-613, 2014. PMID: 24224997. DOI: 10.1016/S0140-6736(13)61950-9

2 Kolberg HC, Loevey G, Akpolat-Basci L, Stephanou M, Fasching PA, Untch M, Liedtke C, Bulsara M and Vaidya JS: Targeted intraoperative radiotherapy tumour bed boost during breast-conserving surgery after neoadjuvant chemotherapy. Strahlenther Onkol 193(1): 62-69, 2017. PMID: 27858093. DOI: 10.1007/s00066-016-1072-y

3 Vaidya JS, Bulsara M, Wenz F, Coombs N, Singer J, Ebbs S, Massarut S, Saunders C, Douek M, Williams NR, Joseph D, Tobias JS and Baum M: Reduced mortality with partial-breast irradiation for early breast cancer: A meta-analysis of randomized trials. Int J Radiat Oncol Biol Phys 96(2): 259-265, 2016. PMID: 27478165. DOI: 10.1016/j.ijrobp.2016.05.008

4 Cosmetic Surgery National Data Bank Statistics (no authors listed). Aesthet Surg J 37(suppl_2): 1-29, 2017. PMID: 283887 34. DOI: $10.1093 /$ asj/sjx076

5 Handel N, Lewinsky BS, Jensen JA and Silverstein MJ: Breast conservation therapy after augmentation mammaplasty: is it appropriate? Plast Reconstr Surg 98(7): 1216-1224, 1996. PMID: 8942907

6 Lafreniere $\mathrm{R}$ and Ketcham AS: Breast carcinoma postaugmentation mammaplasty: therapy with limited surgery and radiation. J Surg Oncol 35(2): 99-103, 1987. PMID: 3586688.

7 Jacobson GM, Sause WT, Thomson JW and Plenk HP: Breast irradiation following silicone gel implants. Int J Radiat Oncol Biol Phys 12(5): 835-810, 1986. PMID: 3086262.

8 Guenther JM, Tokita KM and Giuliano AE: Breast-conserving surgery and radiation after augmentation mammoplasty. Cancer 73(10): 2613-2618, 1994. PMID: 8174060. DOI: $10.1002 / 1097-0142(19940515) 73: 10<2613:$ :aid cncr2820731024>3.0.co;2-9

9 Halpern J, McNeese MD, Kroll SS and Ellerbroek N: Irradiation of prosthetically augmented breasts: a retrospective study on toxicity and cosmetic results. Int J Radiat Oncol Biol Phys 18(1): 189-191, 1990. PMID: 2298621.

10 Victor SJ, Brown DM, Horwitz EM, Martinez AA, Kini VR, Pettinga JE, Shaheen KW, Benitez P, Chen PY and Vicini FA: Treatment outcome with radiation therapy after breast augmentation or reconstruction in patients with primary breast carcinoma. Cancer 82(7): 1303-1309, 1998. PMID: 9529022. 
11 Krishnan L, Krishnan EC, Wolf CD and Jewell WR: Preservation of augmented breasts in patients with breast cancer. Radiographics 13(4): 831-839, 1993. PMID: 8356271. DOI: 10.1148/radiographics.13.4.8356271

12 Lei RY, Leonard CE, Howell KT, Henkenberns PL, Johnson TK, Hobart TL, Kercher JM, Widner JL, Kaske T, Barke LD and Carter DL: External beam accelerated partial breast irradiation yields favorable outcomes in patients with prior breast augmentation. Front Oncol 4: 154, 2014. PMID: 24995159. DOI: $10.3389 /$ fonc. 2014.00154
13 Kuske R: Breast conservation therapy without capsular contracture in young augmented women using interstitial brachytherapy. J Contemp Brachytherapy 6(2): 231-235, 2014. PMID: 25097566. DOI: 10.5114/jcb.2014.43779

Received June 11, 2019

Revised June 27, 2019

Accepted June 28, 2019 